Article

\title{
Assessing the Implementation of Best Productivity Practices in Maintenance Activities, Shutdowns, and Turnarounds of Petrochemical Plants
}

\author{
Pramesh Krishnankutty ${ }^{1}{ }^{\mathbb{D}}$, Bon-Gang Hwang ${ }^{2, *}$, Carlos H. Caldas ${ }^{3}$, Sriya Muralidharan ${ }^{2}$ and \\ Daniel P. de Oliveira ${ }^{4}$ \\ 1 Productivity Council, Singapore Chemical Industry Council Limited, 8 Jurong Town Hall Road, \#25-04 The \\ JTC Summit, Singapore 609434, Singapore; pramesh@scic.sg \\ 2 Department of Building, School of Design \& Environment, National University of Singapore, 4 Architecture \\ Drive, Singapore 117566, Singapore; sriyamurali92@outlook.com \\ 3 Department of Civil, Architectural, and Environmental Engineering, The University of Texas at Austin, \\ ECJ 5.210, Austin, TX 78712, USA; caldas@mail.utexas.edu \\ 4 Construction Industry Institute (CII), 3925 W, Braker Ln, Austin, TX 78759, USA; \\ daniel.oliveira@cii.utexas.edu \\ * Correspondence: bdghbg@nus.edu.sg; Tel.: +65-6516-7488
}

Received: 11 January 2019; Accepted: 21 February 2019; Published: 26 February 2019

\begin{abstract}
This paper describes the development of a method to assess the level of implementation of best productivity practices in the petrochemical industry. The proposed methodology focuses on construction, maintenance activities, shutdowns, and turnarounds. Its novelty and importance are emphasized by the lack of productivity studies that target these types of projects. This article reports the research methodology steps including tool development and detailed case study assessments of projects in Singapore. The approach involved the verification of best productivity practices and the development of an assessment method designed to fit the characteristics of petrochemical projects. The assessment points out productivity practices with low implementation levels and provides recommendations to increase their usage. The results showed that the level of implementation of productivity practices in the petrochemical projects investigated was $68.42 \%$, out of a maximum score of $100 \%$. Practices related to Material Management and Equipment Logistics received the lowest scores and recommendations on how to bridge this productivity practice implementation gap were provided. The adoption of the Best Productivity Practices Implementation Index (BPPII) as a Productivity management tool will help the petrochemical plants to improve productivity in their projects and to be resilient during the pre-planning phase. This should also allow the petrochemical industry to attract more investments and remain competitive in order to be sustainable. The identification and analysis of practices related to maintenance activities, shutdowns, and turnarounds of petrochemical plants will significantly contribute to the body of knowledge on best productivity practice.
\end{abstract}

Keywords: performance management; productivity; best practices; construction; maintenance; shutdowns; Singapore

\section{Introduction}

Achieving improved labor productivity has become one of the key quests for several world economies. This is attributable to the fact that labor cost accounts for a significant portion $(30-40 \%)$ of the total construction cost [1]. Taking into account social factors such as the rapid aging of 
the population and immigration issues for foreign labor in some countries [2], there is a need for governments to adopt a productivity-driven growth model in order to be sustainable.

In the case of Singapore, the Economic Strategies Committee (ESC) set a goal to achieve $2 \%$ to $3 \%$ annual productivity growth for the decade of 2010-2020 [3]. This could only be achieved by improving productivity in key drivers of the Singapore economy. Therefore, it is essential to focus on the petrochemicals industry, which contributes nearly $34 \%$ of the total manufacturing output [4]. Jurong and Bukom islands are hosts to several of the world's leading petrochemical companies, such as ExxonMobil, Singapore Refining Company (SRC), Chevron, Petrochemical Corporation of Singapore (PCS), Mitsui Chemicals, and Shell. The investments in Jurong Island alone exceeded 35 billion Singapore Dollars in 2014 [5].

Moreover, the expenses relating to the labor accounts for the largest share of the total business costs. Together with work given out and royalty payments, these three components account for $64 \%$ of the business costs of large enterprises and $71 \%$ of the business costs of small- and medium-sized enterprises (SMEs). The unit cost of labor (manufacturing and service sector combined) also increased by $2.8 \%$ owing to a decrease in productivity and raised compensation [6].

As part of the government's mission for enhanced labor productivity, the Process Construction and Maintenance Management Committee (PCMMC) was formed in collaboration with plant owners, major contractors, Singapore Chemical Industry Council, and the Association of Process Industry (ASPRI) in 2013. The committee aims to improve labor and project productivity in the Process Construction and Maintenance (PCM) Sector [4].

In order to attain its aim, the Productivity Council of Singapore has partnered with the Construction Industry Institute (CII) and National University of Singapore (NUS) for a three-year initiative. This initiative enabled CII-NUS to introduce best practices, metrics, and benchmarking for the Process, Construction, and Maintenance (PCM) industry [7]. Each year, the Productivity Council worked on a project targeted at improving overall productivity.

The research project aimed to explore productivity improvement from several perspectives. In the first year of this project, Activity Analysis was introduced a research methodology to monitor the time expended by workers on-site and identify productivity inhibitors which can be mitigated or eliminated thereby enhancing the time spent on direct-work $[8,9]$. This practice was tailor-made to suit the Singapore site conditions and provided key insights into labor productivity. The results concluded that majority of the work hours on-site has been consumed on supporting activities such as preparatory work, material handling, traveling, and waiting for instruction. The trend also highlighted that there is a lack of detailed construction execution planning at the workface [9]. Therefore, the research team proposed to conduct studies on assessing the planning and implementation levels of key practices needed to ensure high levels of labor and construction productivity. While Activity Analysis tackles productivity improvement using a bottom-up strategy (i.e., from site-work observations to management) it is also useful to explore the possibilities of productivity improvement from the organization level. Furthermore, the results of the Activity Analysis study in Singapore also identified several reasons for low-productivity that may be linked to effective management/planning. The goal of this paper is to present first results from the new research program and to identify the areas of improvement for the owners and mainly the contractors for improving their tool time and reducing the time consumed on other supporting activities on-site. Previous studies have shown that effective management practices have resulted in successful construction projects [10]. However, the ineffective implementation of such practices may not yield the desired results [11]. During the Activity Analysis study in Singapore [9], it was apparent that most maintenance, shutdown, and turnaround projects in Singapore do not effectively implement historically successful productivity practices, and were seldom implemented consistently from project to project. While increasing direct work percentage would offer an opportunity for achieving a breakthrough in productivity, improving the resilience of the contractor organization towards future challenges is also important. These challenges faced in the industry requires a tool to measure the performance of the organization during the pre-planning 
phase to reduce costs, mitigate skilled labor shortages, improve project schedule performance, and to be resilient towards future challenges by recommending strategies improvement.

To help the industry to address this problem and standardize the site planning procedure, the research team developed a method and metric for assessing the planning and implementation levels of the essential practices needed to ensure high levels of productivity of the craft workers in petrochemical projects. This method is called the Best Productivity Practices Implementation Index for Petrochemical Projects (BPPII-Petrochemical).

The Best Productivity Practices Implementation Index (BPPII-Industrial) method was first proposed by the Construction Industry Institute (CII) to assess the planning and implementation of management practices that have been widely accepted to improve craft worker productivity. This BPPII-Industrial method included 53 best productivity practices also referred to as elements, which were grouped in six categories: (1) materials management, (2) equipment logistics, (3) craft information systems, (4) human resources management, (5) construction methods, and (6) environment, health, and safety. This method was developed to allow project management to quantitatively assess the existing implementation levels of the practices and also offer recommendations for improvement based on the BPPII-Industrial score. However, since the original BPPII-Industrial tool focused on industrial projects in North America, there were limitations cited when using this tool for various types of projects and project locations [11].

This research examines the BPPII-Industrial approach developed by CII and adapts it to develop models that are best suited to petrochemical construction projects, maintenance activities, shutdowns, and turnarounds. The BPPII-Petrochemical method is designed to provide both initial and in-progress assessments of how much a petrochemical project's planning and best practice implementation influence craft productivity. Moreover, contractors are finding it increasingly difficult to identify new practices, tools, materials, and technologies to improve productivity in order to remain competitive [12]. Given Singapore's keen drive towards productivity improvement and establishing itself as the global leader in petrochemicals, it is indeed worthwhile to implementing BPPII-Petrochemical in Singapore.

This study, which may be construed as an extension of the existing work on BPPII-Industrial [11], aims to: (1) Further investigate the existing BPPII-Industrial method and its suitability for petrochemical plant environments; (2) Develop the new BPPII-Petrochemical method taking into consideration the nature of maintenance activities, shutdowns, and turnarounds; (3) Validate the new BPPII-Petrochemical through its implementation in pilot projects and quantitative evaluation of the existing implementation levels with all the stakeholders; (3) Investigate the practices that seem to lag in terms of implementation; and (4) Provide necessary recommendations for improving the BPPII-Petrochemical score. The findings of this study provide a baseline for the Singapore industry to benchmark their planning and implementation efforts, as well as to accelerate productivity. The unique contribution of this study would be to identify, and validate practices that have the potential to improve productivity on petrochemical construction, maintenance activities, shutdowns, and turnaround projects.

\section{Literature Review}

\subsection{Background}

Singapore is a small country with an open economy, with limited resources which are highly dependent on services and easily influenced by global events [13]. Studies conducted among thirty-two contractors in Singapore noted that the contractors do not conduct performance measurement on a regular basis. In addition, the study also highlighted the need for standardized performance measurement format with uniformity in the calculation of performance metrics [14]. The main contractors in Singapore mentioned that the extensive usage of sub-contractors as one of their principal challenges towards productivity measurement and that the subcontractors should take this up as an initiative [15]. 
Pheng et al. [16] studied the awareness of early contractor's involvement (ECI), to review its merits, and to establish its feasibility as a procurement method by conducting studies in Singapore's building industry. The study concluded by identifying ECI as one of the crucial factors for on-site productivity improvement in Singapore. Hwang and Soh [17], investigated the challenges encountered by Singapore contractors in measuring trade-level productivity. The findings suggested the industry to streamline productivity measurement methods and focus on important trades, conduct training, and workshops on developing a productivity measurement system for firms, creating a culture within contractors for productivity measurement and reporting, and to streamline productivity measurement as a guideline.

Caldas et al. [11], highlighted the need for the development of a BPPII method specific to a country or region and emphasized the need for customization of the method by adding country-specific BPPII elements and their respective weights to reflect different project types and their characteristics. Hence, the BPPII method should be freshly developed by taking into consideration the factors and management practices affecting on-site productivity in the Singapore construction sector with the help of the methodology described above. The study could be carried out in conjunction with Activity Analysis, where pre-implementation of recommended procedures could be used to analyze productivity barriers. Based on this study, the implementation strategy could be developed through the BPPII-Petrochemical method.

\subsection{Need for Productivity Improvement}

Productivity is a typical measure that is often used to evaluate organizational performance and excellence. The backbone of all productivity measurements and the principal metric is the generated output divided by input [18]. Input is usually represented by labor-hours. Prior to developing strategies for productivity improvement, it is essential to know the craft workers need and the factors affect their performance on-site [19]. However, craft workers input and the issues affecting their daily work on-site have been rarely studied in maintenance, shutdown, and turnaround environments. Studying and understanding the factors influencing productivity, from the workforce perspective, can help the site management team to effectively plan and allocate resources, support craft workers by motivating them, and augment their commitment towards improving productivity on-site. The on-site management team is in a perfect position to understand the need for productivity improvement and also identify the loss or gain of productivity at the workface and how it can be improved.

\subsection{Parameters Influencing Labour Productivity}

A qualified workforce is critical for owners and contractors to complete a project within the specified budget in a safe and productive manner. On-site planning and training for craft workers have a significant influence on labor productivity [20]. Koch and McGrath [21] studied the connection between human resource management practices and firm-level outcomes. The study highlighted that human resource management policies have psychological significance to the productivity of its employees. Thomas and Završki [22], conducted a productivity study among the U.S. construction companies to analyze and compare the effects of material management practices. The study reported that ineffective material management practice of sub-contractors can incur productivity loss similar to the large industrial contractors. In the Australian construction industry, Loosemore [23], investigated the determinants of construction productivity from a subcontractor's perspective. The study emphasized the importance of adopting a culture of productivity improvement and the need for nurturing across the business and supply chain if productivity is to be improved.

\subsection{Lack of Proper Method for Productivity Improvement and Management}

Nasir et al. [24], reported the importance of conducting productivity improvement studies across different project types. Additionally, the study highlighted the difficulties in benchmarking productivity among contractors and suggested to develop a web-based method for benchmarking 
productivity practices. The tool may include functions including facilitating the input data, generating a report and maintain empirical data over time for benchmarking purposes. Moreover, Zhang et al. [25], developed an internal benchmarking model to consistently benchmark construction productivity and practices that influence productivity and address the improvement potential of productive practices. The study also recommended conducting productivity studies across different project types to extract meaningful information. Caldas et al. [26], conducted studies to identify material management techniques for the current and emerging practices in the capital projects industry. The study identified the increasing level of maturity, formality, and systematization of the approach to materials management by construction companies and justified that there is a need for an electronic tool which provides specific guidelines, strategies for improvement, protocols, and procedures, apt for a futuristic materials management database.

\subsection{Best Practice Productivity Implementation Index (BPPII)}

The BPPII is a metric to measure how effectively the methods, tools, and strategies known to improve construction productivity are being implemented on-site. The process of identifying various practices that positively affect productivity and improve performance at a project level can be termed as productive practices [27]. Over the years CII has developed a various set of best practices to improve performance on-site. The BPPII is a method containing a comprehensive list of best practices, developed to help project managers or superintendents in planning productivity-enhancing job site activities [26,27]. It is also a metric to measure how effectively the methods, tools, and strategies which are known to improve construction productivity are being implemented on a construction job site [28]. These practices were identified through an extensive literature review and in consultation with industry experts and have been proven to impact productivity positively. The practices were then grouped together into a formalized set of BPPII categories, sections, and elements. Each individual category and their elements represented a specific practice that is known to improve productivity. Identifying strong and weak practices may help to trace individual efficiency and technical change in each sector. For example, weaker sectors can learn from the stronger ones and better understand their capabilities. BPPII is designed for use at the end of the Front-End Planning (FEP) phase and at the beginning of the execution phase to support in the preparation of a Project Execution Plan (PEP). The method may be used by a construction planning team to assist in the planning and implementation of the best practices for improving craft productivity on industrial construction projects. It can also be used during the execution phase for continuous assessment and improvement.

\section{Tool Development and Methodology}

Previous developmental studies on BPPII were carried out specifically for the industrial and infrastructure construction sectors [11]. However, the original BPPII methods can be adapted to encompass different project types and locations. The development and validation of the new BPPII-Petrochemical method included the following steps:

(a) Identify best productivity practices and management practices affecting on-site productivity for the petrochemical sector through literature review along with expert consultation.

(b) Identify new practices that can improve productivity and verify the exiting BPPII practices.

(c) Define weights to assess the relative importance of these practices and to develop the BPPII-Petrochemical assessment method with petrochemical industry and project-specific scoring for three different project types.

(d) Validate the BPPII-Petrochemical metric by obtaining data on various pilot projects' scores.

(e) Analyze the validate the pilot projects data to obtain the results and identify which best practices are implemented, how they are implemented at the organizational level and identify the practices which needs to be implemented in order to improve project performance and productivity. 
In order to adapt the original BPPII method to suit the petrochemical industry, this project analyzed and evaluated various CII research projects to develop guidelines and present examples of innovative best practices. The research methodology included a synthesis of relevant literature and experience, workshops, survey-based weighting, and finally a statistical analysis of BPPII-Petrochemical score versus the BPPII-Industrial weights. The research methodology included the structuring and comparison of results from a range of best practices with U.S contractors as their focus. The projects that were examined had the following themes in common: training needs, strategies and methods, and technical requirements. The models were then disseminated and evaluated in a practical manner among industry professionals for their input and to calculate the relative importance index (RI).

The categories and the elements of the BPPII-Petrochemical were developed based on the knowledge and experience of the researchers and industry experts and are based on the scientific validation of the Singapore construction practices, found to have a significant positive impact on construction productivity. The BPPII-Petrochemical was developed to help the project managers or superintendents to execute these management practices and plan on-site activities.

An extensive background review was performed on factors affecting labor productivity and practices improving craft productivity. Second, productivity experts were consulted to help identify the essential practices needed to ensure high craft productivity on industrial projects. In addition to the extensive literature review, the research team validated the suitability of the existing BPPII-Industrial method through industry experts and professionals. An interview form was developed and circulated to nine professionals who possessed more than 20 years of industry experience in maintenance, shutdown, and turnaround projects in Singapore. The experts were also trained on the definitions and need for each element in the existing method. The interview form enabled the interviewees to evaluate the relevance and importance of the existing 53 BPPII-Industrial elements in the context of various different project types (i.e., Construction, Maintenance, and Shutdown/Turnaround). The interview form also had provisions for recommending new elements, which can be added to reflect the specific characteristics of the petrochemical industry. Subsequent to the survey response, the participants were also interviewed face-to-face by the research team individually to validate the responses. The team used the validated inputs to calculate the average level of impact for each element across all three project types. Based on the survey results, the research team decided to retain all existing elements from the original BPPII-Industrial method for the BPPII-Petrochemical method. During the calculation process, the team also took the following actions:

- In addition to calculating the mean scores, the team derived the perfect score for each category and section and all 53 elements.

- By calculating the perfect score for each element, the team could then determine individual scores for Levels 0 through 5.

- The team conducted statistical tests to compare the BPPII-Petrochemical weighting against the BPPII-Industrial weighting.

Additionally, several new elements were recommended by the industry experts so as to make the method reflect the site conditions and management practices implemented in petrochemical plants. The research team members extracted the new elements recommended by participants and studied each element separately to assess its suitability. Finally, 13 new elements were selected through a rigorous review process in order to be added to the new BPPII-Petrochemical method.

Building on the inputs from experienced industry professionals, the research team customized the original BPPII-Industrial method of six categories and 53 elements to serve the petrochemical sector. The new BPPII-Petrochemical method included the following 13 elements, reaching a total of six categories and 66 elements, and the team modified the weightings from the original method for all three project types. 
In the process of identifying the new elements, the research team together with the experienced industry professionals conducted various review meetings to understand the need for the development of the new elements. First, to discuss the need for the induction of new elements and second, the identification of level description methodology for the new elements. The expertise and knowledge of the research team members were used to select and obtain inputs to prioritize and organize the new management practices (elements). Literature review was used extensively to accurately define and describe the elements. In addition, the research team members reviewed, adjusted, and refined the elements descriptions. The task of identifying the new elements were based on the concept of including Automation and integration as the key focus areas. The list of twenty new elements were identified based on the inputs from various industry members. These new elements were individually studied on the suitability of development of levels and interviews were conducted to identify the current level of implementation in the industry. Leveraging on the experience of the industry professionals who participated in this study, 13 new productivity practices (i.e., elements) were identified to be relevant for the BPPII-Petrochemical method). The industry experts selected thirteen elements from the list based on their suitability and applicability to the petrochemical industry and to the Singapore context.

The following table (Table 1) shows the newly developed elements added to the BPPII-Petrochemical method. A detailed discussion of the newly added elements is provided in the next section.

Table 1. New elements in the Best Productivity Practices Implementation Index for Petrochemical Projects (BPPII-Petrochemical) method.

\begin{tabular}{|c|c|c|}
\hline & Sections and Categories & Elements \\
\hline I & $\begin{array}{l}\text { Materials Management } \\
\text { A. Material Management Systems }\end{array}$ & $\begin{array}{c}\text { 1.A.5. Pre-fabricated material tracking } \\
\text { 1.A.6. Material issuing procedure \& material usage } \\
\text { tracking } \\
\begin{array}{c}\text { 1.B.4. Centralized ware house on site, including storage for } \\
\text { fabricated materials }\end{array} \\
\begin{array}{c}\text { 1.B.5. QA/QC inspection \& assessment and NDT testing \& } \\
\text { tracking plan }\end{array}\end{array}$ \\
\hline II & $\begin{array}{l}\text { Equipment Logistics } \\
\text { B. Machinery Availability }\end{array}$ & $\begin{array}{l}\text { 2.B.3. Construction machinery tracking } \\
\text { 2.B.4. Fuel top up schedule for equipment and machinery } \\
\text { 2.B.5. On-site construction equipment lay down area }\end{array}$ \\
\hline III & $\begin{array}{l}\text { Craft Information Systems } \\
\text { A. Short Interval Planning } \\
\text { B. Workface Planning } \\
\text { C. Constructability Review }\end{array}$ & $\begin{array}{l}\text { 3.A.2. Centralized planning, work prioritization, and } \\
\text { process control } \\
\text { 3.B.9. Quality control systems } \\
\text { 3.C.3. Work interface review }\end{array}$ \\
\hline IV & $\begin{array}{l}\text { Human Resource Management } \\
\text { A. Training and Development }\end{array}$ & $\begin{array}{l}\text { 4.A.3. Supervisors and foremen skills development and } \\
\text { training }\end{array}$ \\
\hline V & $\begin{array}{l}\text { Construction Methods } \\
\text { B. Start-Up, Commission, } \\
\text { and Turnover Plan }\end{array}$ & $\begin{array}{l}\text { 5.B.4. Process-Interface (process technician standby) } \\
\text { 5.B.5. Planning for shut down (plan for transient s/o } \\
\text { operation) }\end{array}$ \\
\hline
\end{tabular}

A comprehensive review of the related literature was also performed to describe the elements accurately. The new elements were of relevance to the maintenance and shutdown/turnaround environments satiating the main aim of this study. The various levels of implementation of these elements were defined by examining the existing technologies available in the market and possible future advancements in the technologies. The final version of the BPPII-Petrochemical tool included the identified practices that are essential to properly plan and implement the element in order to help 
the project management team to objectively evaluate the level of planning and implementation of the element. The detailed definitions of the new elements were as follows.

\subsection{Materials Management (I)}

Poor material management has been identified by Thomas et al. [29], as a factor that significantly lowers craft worker productivity. Literature highlights that nearly one-third of worker time is wasted either in the search for components or in the wait to make use of the components. Consequently, this scenario has also been shown to decrease worker motivation and also increase the time required to complete a task. The above-mentioned factors can negatively impact critical project parameters of cost and schedule. Hence, the use of information and sensing technologies may augment construction labor productivity by offering an improved degree of control over materials on-site. Moreover, a field trial study by Grau et al. [30], also validated the potential of automated site material tracking practices.

In addition to efficient material tracking, the industry practitioners who participated in this study also emphasized the need for effectual quality inspection and testing systems for materials delivered to the plant site. They highlighted that the implementation of (technology-assisted) inspection plans would facilitate easy availability of quality/inspection data to all stakeholders and also enable the management to make advance decisions. Such technologies have been explored in the precast industry [31], and it may also be worthwhile to explore its application in the petrochemical construction and maintenance industry.

In light of the above, the following new elements were incorporated into the BPPII-Petrochemical to make it more comprehensive than the previous version.

\subsubsection{Pre-Fabricated Material Tracking (I.A.5)}

It was identified that a method for tracking and locating all pre-fabricated materials on-site was necessary. This method must include information on the material quantity, criticality of schedule, the complexity of the project, etc. Some examples of the technologies include Barcodes, GPS (Global Positioning System) [32], and RFID (Radio-frequency identification) tags [33]. The levels of implementation for prefabricated material tracking ranged from no defined method for tracking (Level 1), paper-based tracking (Level 2), and ultimately to the use of an integrated software system which can be used by all contractors to track the item right from the manufacturing stage (Level 5).

\subsubsection{Material Issuing Procedure and Material Usage Tracking (I.A.6)}

In order to maintain control and organize materials on the site, this study found that a defined material issuing procedure and usage tracking system was critical. Material issuance and tracking could be implemented through a paper-based system (Level 2) or software systems (Level 3 to 5). Depending on the level of sophistication of the paper/software systems the various levels of implementation were defined. The levels examined the integration of the software systems with the company's other information technology systems, real-time update capability on the item status and availability (Level 5).

\subsubsection{Centralized Warehouse On-Site, Including storage for Fabricated Materials (I.B.4)}

The industry professionals involved in this study also highlighted that the maintenance of an accessible centralized warehouse may improve coordination and lower waiting time for materials that would otherwise need to be delivered from an off-site location. The levels of implementation of this element ranged from designation of a central warehouse (Level 1), existence of a procedure to track material flow from and to the warehouse (Level 2) and ultimately the use of software applications to track and update material status (Level 3-4) and also organize them based on criticality (Level 5). 
3.1.4. QA/QC Inspection and Assessment and Non-Destructive Testing (NDT) and Tracking Plan (I.B.5)

Establishment of robust quality assurance and control plans to track and maintain the quality of materials delivered to the site was noted to be critical as ineffective plans may lead to unscheduled downtime, delays, and increased cost. This was also necessary for NDT and tracking on-site. The levels of implementation of this element were defined from Level 1 (no documentation of the plans), Level 2 (Inspection and test plans defined on a case-to-case basis) finally to Level 5 (existence of an automated system for real-time update and communication of the inspection and test results).

\subsection{Equipment Logistics (II)}

In the preceding studies on construction equipment management, it was pointed out that proper availability [34] and site management of construction equipment [35], would positively impact labor productivity. Specifically, the use of GPS [36], and RFID technologies [37], for tracking construction machinery have been consistently cited in construction research. Moreover, advanced tracking of on-site construction machinery could facilitate: an improvement in the safety performance [36], job site layout and prevent theft [38], and also optimize the utilization of construction equipment. Based on their extensive practical experiences on petrochemical plant sites, the industry practitioners also mentioned the need for the development of a fuel top-up schedule for all construction machinery. This element was not present in the previous BPPII-Industrial method. However, the practitioners opined that the development of such a schedule would ensure the availability of fuel and mitigate any project delays that may arise due to low fuel. The practitioners also advocated for the allocation of an on-site equipment laydown area accessible to all plant locations in order to achieve efficient field operation. Therefore, three new elements encompassing the above-mentioned aspects were included in the new BPPII-Petrochemical method.

\subsubsection{Construction Machinery Tracking (II.B.3)}

This study emphasized the creation of a system for tracking all construction machinery and assets as critical fiscal risks and disruptions to the construction process can occur in the event of lost or stolen machinery. The system furthermore would enable effective on-site coordination thereby optimizing work hours and fuel costs. The tracking system may involve technologies such as GPS, smart route planning, motion sensors, and vehicle theft prevention systems. The levels of implementation of this tracking ranged from paper-based systems (Level 2) to highly sophisticated software systems (Level 5) equipped with GPS (for locating machinery and sending alerts to personnel on the machinery location), motion sensors (to ensure the machinery is only being used for the designated work), and theft prevention systems (to alert the project team in the event of a theft).

\subsubsection{Fuel Top-Up Schedule for Equipment and Machinery (II.B.4)}

As mentioned earlier, effective fuel management would ensure the adequate supply of fuel to for the equipment to perform the designated work. This study highlighted the need for maintenance of a fuel top-up schedule considering the project schedule and resource needs. The schedule could be implemented at various levels such as manual paper tracking (Level 2) or through the creation of fuel top-up tracking software application (Level 3 to 5). Furthermore, the highest level of implementation (Level 5) was defined as the state where the fuel top-up schedule was created and maintained through software applications and motion sensors on the equipment to monitor fuel status.

\subsubsection{On-Site Construction Equipment Laydown Area (II.B.5)}

Designation of an accessible construction equipment laydown area was identified as a critical need for efficient field operations. Hence the study included the provision and proper location of the equipment laydown area as a new element in the BPPII-Petrochemical method. The highest 
implementation level of this element also encompassed organization of the laydown area based on work sequence and usage of software applications for updating construction equipment movements and location (Level 5).

\subsection{Craft Information Systems (III)}

Several researchers $[11,13,26,39]$, emphasized the importance of project information sharing to all the stakeholders in a project, specifically the craft workers. The information integration process though cited to be a challenge would be beneficial to the project in terms of quality improvement and cost reduction. Though the significance of information sharing was identified in the BPPII-Industrial method, the expert participants in this study emphasized the creation of an exclusive BPPII-Petrochemical element evaluating the project planning and flow of information across the project team. The experts also agreed that a work prioritization process with process control systems would facilitate effective information sharing based on the task priority

The guidelines from INGAA (Interstate Natural Gas Association of America) Foundation [40], developed strategies for implementing Quality Control systems in construction projects and highlighted the importance of a Quality Culture in organizations. In addition, the guideline highlights the need for a quality control system with guidance and information on the method of inspection, the inspection intervals and reporting problems and adverse trends to be addressed and required corrective actions. The industry practitioners also opined that evaluation of quality control systems for various project phases would minimize delays and reduce rework.

Interface management between various project stakeholders has been identified as a critical factor impacting the cost and schedules of capital projects and thereby project success [41]. Lenahan [42] studied Turnaround, Shutdown and Outage Management and highlighted the importance of Work interface review for the contractors. This study also recommended the Turnaround manager to conduct a timely review in order to resolve any interface conflicts between different contractors. The implementation of formal interface management practices was also concurred by the professionals interviewed in this study. Hence three new elements encompassing the abovementioned factors were added to the BPPII-Petrochemical method.

\subsubsection{Centralized Planning, Work Prioritization, and Process Control (III.A.2)}

The research team along with the inputs of industry professionals identified that participation of all stakeholders and effective flow of communication between stakeholders was important for the proper execution of site works. Therefore, the study advocated the creation of centralized planning, work prioritization, and their control procedures in the early stages of a project. The various levels of implementation of this particular element included the existence of a documented process (Level 2), use of a planning tool or software application that may or may not be accessible to all stakeholders (Level 3 to 5).

\subsubsection{Quality Control Systems (III.B.9)}

This study added quality control as a new element to the BPPII-Petrochemical tool. It was highlighted that effective quality management of project aspects such as engineering, procurement, QA/QC (Quality assurance/Quality control), construction efficiency, contract compliance, and cost-effectiveness of design would ensure smooth and satisfactory project execution. Quality control methods were defined at various levels ranging from formal paper-based procedures (Level 2) to advanced software systems (Level 3) which may be integrated with other information technology systems of the company and automatically updated the on-site test/inspection results (Level 5).

\subsubsection{Work Interface Review (III.C.3)}

Work interface review was identified by this study as a critical element to improve the on-site performance of all stakeholders involved in planning and/or construction of the project. Effective 
usage of work interface review would reduce the rework, construction delays, poor constructability, etc. Various methods (defined at different levels) for implementing effective work interface review were identified namely:

- Incorporate construction stakeholders during the design phase (Level 2);

- Issue and enforce the use of design standards through the creation of a central database (Level 3);

- Continuous improvement of the design process by the work interface team (Level 4); and

- Effective routes established for the flow of information/communication to ensure the availability of the latest information to all the stakeholders (Level 5).

\subsection{Human Resource Management (IV)}

In addition to the existing elements from [9], highlighting the significance of workforce training and improving worker motivation. The industry practitioners participated in this study cited that the skill development of foremen and supervisors must be included as a best practice. Moreover, Prais and Wagner [43] highlighted that every German craftsman is taught as part of his initial craft training to be conscious of the poor workmanship and late delivery. As the modern technology demands increasingly adaptable and skilled workforce, both at operative and supervisory levels; supervisors and foremen skills development and training were highlighted to be essential.

Supervisors and Foremen Skills Development and Training (IV.A.3)

Effective skills development and training of foremen/supervisors can increase the morale of the site management team. Investment in human capital may prove to be beneficial to the organization should employee turnover rates remain low. The study emphasized that a project team should decide if a training plan should be developed for the same considering project duration, size, and employee turnover. This element may be implemented in various levels including the establishment of a committee to identify training requirements for foremen/supervisors (Level 2), provision of an annual certified skills development and training (Level 3), and also the online availability of these training modules for all craft workers (Level 5).

\subsection{Construction Methods (V)}

One of the main focus areas of this study was to extend the BPPII-Industrial method to maintenance and shutdown/turnaround projects as these projects involved labor extensively. Hence, the research team decided to include an element relating to planning for shutdown activities. Hammed [44] states that planning for shutdown should begin well in advance and it should involve all the departments such as procurement, engineering, maintenance, operations, quality assurance, HSE, security, and administration. This view was also concurred by the maintenance and shutdown/turnaround professionals who participated in this study. Also, the establishment of a Process-Interface (i.e., process technician standby) was also suggested based on the practical constraints and issued faced in the petrochemical facilities during shutdown and maintenance.

\subsubsection{Process-Interface (V.B.4)}

The study identified the requirement of a process-interface technician for ensuring the safe and efficient performance of processes on-site. The various level of implementation of this element was defined based on the responsibilities of the process-interface technician. The duties of the technician may include trouble-shooting (Level 3), active monitoring of the works on-site and ensuring precise documentation and handover between shutdown phases (Level 4 ) and also updating the daily activities on a database resource (Level 5). 


\subsubsection{Planning for Shutdown (V.B.5)}

As the current study focused more on shutdown-turnaround and maintenance activities, it was essential to identify elements critical to such project types. Through consultation with industry experts, it was concluded that a plan (encompassing engineering, procurement, operations, maintenance, quality assurance, and safety and security activities) for shutdown must be included and tracked in the master schedule. Effective planning considering work details, the sequence of works, the definition of personnel roles and responsibilities and clear handover between each activity/shutdown phase was highlighted to be key to project success. The various levels of shutdown planning included consideration for plant utilization in the shutdown (Level 2), planning of manpower and materials for the shutdown (Level 3), utilization of a central database to store project planning details and establishment of a communication protocol within the project team (Level 4). Advanced levels of planning may also include contractor competency screening, contingency, and change control plans and also protocols for quality control systems, communication, and management (Level 5).

\subsection{Development of Weights for the BPPII-Petrochemical Elements}

Weights of the elements of the BPPII-Petrochemical method were calculated based on industry experts' perception of the element's impact on labor productivity. The practice of relying on expert opinion for the development of weights for decision support tools has been previously cited in the literature [45]. An interview form was developed for this purpose and circulated to the same nine experienced industry professionals who had been contacted previously. In order to extract meaningful information, face to face expert consultation and discussion with the industry experts were conducted. During the discussion, the survey participants were made aware of the objective of the survey and were requested to rate each particular element with respect to its impact on labor productivity [27], on a scale of 1 to 5 where the 1 corresponded to least impact using a survey form as shown in Appendix A, Figures A1 and A2. The participants were also required to provide the importance of each element with respect to the project type, i.e., construction, maintenance, and shutdown/turnaround and also to understand the current maturity level of the productivity practice (elements) on-site, etc. and then the members shall provide their response through email. The survey data was then utilized to calculate the average importance of each element, section, and category. Relative weights of each element with respect to the other were calculated based on their relative significance to productivity.

The relative importance weights (RIW) of each category were evaluated as the ratio between the individual coefficient and the sum of all category coefficients by the following formula:

$$
R I W=\frac{r_{i}}{\sum_{i=1}^{n} r_{i}} X 100
$$

where $r_{i}=$ Pearson's correlation coefficient; and $n=6$ (for six categories)

Subsequently, the maximum score (corresponding to implementation level 5 on a 1 to 5 scale) for each of the 66 elements (53 original and 13 new elements) was calculated under each project environment. The research team set the maximum attainable BPPII-Petrochemical score as 2000 and the lowest at 0 . This conformed to the best level of implementation of all the practices in the tool and poorest level of implementation, respectively (i.e., all elements were not applicable). The following Table 2 shows the maximum score of the six categories across shutdown turnaround and maintenance projects. 
Table 2. Maximum Scores of BPPII-Petrochemical Categories for Construction, Maintenance, and Shutdown/Turnaround Projects.

\begin{tabular}{ccccc}
\hline & Categories & New Construction & Maintenance & Shutdown/Turnaround \\
\hline I & Materials Management & 342 & 317 & 338 \\
II & Equipment Logistics & 300 & 302 & 315 \\
III & Craft Information Systems & 349 & 323 & 320 \\
IV & Human Resource Management & 327 & 345 & 324 \\
V & Construction Methods & 323 & 320 & 329 \\
VI & Environment Safety and Health & 359 & 392 & 375 \\
& Total & 2000 & 2000 & 2000 \\
\hline
\end{tabular}

All elements that were "Not Applicable" to a particular project were assigned a score of zero. An implementation of level 1 for each element was assigned a score 1 . The scores for rest of the five levels of implementation (namely levels 2,3, and 4) of each practice was calculated using the method of linear interpolation and rounded off to the nearest whole number. The same methodology was used for all the three project types.

The following Table 3 shows the scoring for the various elements under the "Material Management" category for Maintenance projects.

Table 3. Example Scores for various implementation levels in Material Management Category.

\begin{tabular}{|c|c|c|c|c|c|c|}
\hline \multicolumn{7}{|c|}{ I-Materials Management } \\
\hline \multicolumn{2}{|l|}{ Section } & \multicolumn{5}{|c|}{ Implementation Level } \\
\hline Element & 0 & 1 & $2^{1}$ & 3 & 4 & 5 \\
\hline B. Receipt and Inspection of Materials & \multicolumn{6}{|c|}{ Weighted Scores } \\
\hline 1. B.1. Material Inspection Process & 0 & 1 & 9 & 17 & 25 & 32 \\
\hline 1. B.2. Material Inspection Team & 0 & 1 & 8 & 15 & 22 & 9 \\
\hline 1. B.2. Post-receipt Preservation and Maintenance & 0 & 1 & 8 & 16 & 23 & 30 \\
\hline $\begin{array}{l}\text { 1. B.4. Centralized Onsite Warehouse; Fabricated } \\
\text { Materials Storage }\end{array}$ & 0 & 1 & 7 & 13 & 20 & 26 \\
\hline $\begin{array}{c}\text { 1. B.5. QA/QC Inspection \& Assessment; NDT } \\
\text { Testing \& Tracking Plan }\end{array}$ & 0 & 1 & 8 & 16 & 23 & 30 \\
\hline
\end{tabular}

Moreover, a simulation study with five projects was also conducted to analyze the consistency between the BPPII-Petrochemical and BPPII-Industrial scoring methodologies. The two methods were found to be consistent with each other.

Subsequently, the research team developed the BPPII-Petrochemical too utilizing Microsoft Excel and Visual Basic for all three types of projects (Construction, Maintenance, and Shutdown/Turnaround) encountered in the petrochemical industry. This tool developed on Microsoft Excel, a commonly available platform, contained the following tabs: (1) Introduction, (2) User Guide, (3) Background-BPPII Description, (4) Input-BPPII Rating, (5) Output-BPPII Reporting, and (6) Output-BPPII Comments. The first three tabs explained the various BPPII elements and provided a guide to use the method. The key section of the method was the "Input-BPPII rating" which required the input from the owner/contractors. The BPPII tool automatically generated preliminary results in the "Output-BPPII Reporting" tab as soon as the user inputs the data.

The BPPII method identified the implementation level for each practice and summarized these results, together with recommendations that could help each participating company capture the most notable findings from the analysis (Output-BPPII Comments).

\subsection{Project Evaluation Using the BPPII-Petrochemical Method}

A project team may evaluate their level of implementation of best practices using the simple Excel method designed by this study. Each element in the BPPII-Petrochemical has five implementation levels. An implementation level of Level 0 was also provided in the method in case a particular 
element was deemed not applicable to a project. The implementation levels were clearly defined and the description was also designed to appear whenever the user(s) clicked a specific element in the Excel tool (shown in Appendix A and Figures A5 and A6). An example of the description of various implementation levels is given in Figure 1 below. The score for each of the elements was calculated according to its implementation level and weight as mentioned in the previous section. The sum of all the element scores would determine the project's BPPII-Petrochemical score.

\begin{tabular}{|c|c|}
\hline \multirow{2}{*}{\multicolumn{2}{|c|}{$\begin{array}{l}\text { 5.B.5 Planning for shutdown (plan for transient s/o operation) } \\
\text { Planning for shutdown should be included in the master schedule for tracking purposes and include } \\
\text { activities for: procurement, engineering, maintenance, operations, quality assurance, HSE \& security, } \\
\text { and administration. The sequence of the shutdown should be considered in large facilities. The key } \\
\text { to success is organization and discipline, clearly defined roles and responsibilities, clear handover } \\
\text { between each activity or shutdown phase and attention to detail should be considered during the } \\
\text { planning stage. }\end{array}$}} \\
\hline & \\
\hline Level - 0 & Planning for shutdown is not applicable \\
\hline Level - 1 & eated a plan for shutdown \\
\hline Level - 2 & $\begin{array}{l}\text { Project team has planned and defined the complete scope of work for shutdown but the } \\
\text { plant utilization has not been considered. }\end{array}$ \\
\hline Level - 3 & $\begin{array}{l}\text { The plant utilization has been considered during the Pre-Shutdown Activities (Planning } \\
\text { and Scheduling) and the project team has preplanned the complete scope of work, } \\
\text { itemized list of required materials and manpower. }\end{array}$ \\
\hline Level - 4 & $\begin{array}{l}\text { Continuation of Level 3, plus, centralized database to store project planning and details } \\
\text { of other information's such as materials, manpower etc. and communication strategy } \\
\text { with all the project team with specific protocol has been developed. }\end{array}$ \\
\hline Level - 5 & $\begin{array}{l}\text { Continuation of Level 4, plus, competency screening (are your contractors skilled and } \\
\text { competent) of all contractors and risk ranking (for parties responsible for conducting } \\
\text { high-risk activities), contingency planning, protocol for quality control systems, change } \\
\text { control plan (any planned changes to the plant and equipment are approved well in } \\
\text { advance) and Control, communication supervision and management are considered } \\
\text { during the planning stage. }\end{array}$ \\
\hline
\end{tabular}

Figure 1. BPPII-Petrochemical element example with level descriptions.

In addition to tool development, the research team developed a table consisting of key project personnel's best suitable to answer the BPPII elements based on the six categories. As the BPPII-Petrochemical is a project-based tool input from both owners and contractors is essential in order to achieve successful data collection and validation. Figure 2 below clearly depicts the list of various project team members under each subcategories. These members from each of the thirteen pilot projects were interviewed together and separately as part of an extensive data collection process. 


\begin{tabular}{|c|c|c|c|}
\hline & Sections and Categories & Contractor & Owner \\
\hline \multirow{4}{*}{ I } & MATERIALS & & \\
\hline & MANAGEMENT & & \\
\hline & $\begin{array}{l}\text { Material Management } \\
\text { Systems }\end{array}$ & $\begin{array}{l}\text { Procurement Engineer and } \\
\text { Site Engineer }\end{array}$ & Procurement Engineer \\
\hline & $\begin{array}{c}\text { Receipt and Inspection of } \\
\text { Material }\end{array}$ & QA/QC Inspector & QA/QC Inspector \\
\hline \multirow[t]{3}{*}{ II } & EQUIPMENT LOGISTICS & & \\
\hline & Site Tool Management & Site Engineer/ Supervisor & Supervisor \\
\hline & Machinery Availability & Site Engineer/ Supervisor & Supervisor \\
\hline \multirow[t]{4}{*}{ III } & $\begin{array}{c}\text { CRAFT INFORMATION } \\
\text { SYSTEMS }\end{array}$ & & \\
\hline & Short Interval Planning & Planner /Site Engineer & Planner \\
\hline & Workface Planning & Planner /Site Engineer & Planner \\
\hline & Constructability Review & Project Manager/ Engineer & Project Manager/ Engineer \\
\hline \multirow[t]{5}{*}{ IV } & $\begin{array}{c}\text { HUMAN RESOURCE } \\
\text { MANAGEMENT }\end{array}$ & & \\
\hline & Training and Development & HR manager & HR Executive \\
\hline & Behavior & HR manager & HR Executive \\
\hline & Organizational Structure & HR manager & HR Executive \\
\hline & Employment & HR manager & HR Executive \\
\hline \multirow{6}{*}{$\mathrm{V}$} & CONSTRUCTION & & \\
\hline & METHODS & & \\
\hline & $\begin{array}{l}\text { Sequence and Scheduling of } \\
\text { Work }\end{array}$ & Planner & \\
\hline & $\begin{array}{c}\text { Start-Up, Commission, and } \\
\text { Turnover Plan }\end{array}$ & QA/QC Inspectors & Project Manager/ Engineer \\
\hline & Technology Investigation & Project manager & Project Engineer \\
\hline & Site Layout Plan & $\begin{array}{c}\text { Logistics manager and } \\
\text { Project Manager/ Engineer }\end{array}$ & Planner \\
\hline \multirow[t]{4}{*}{ VI } & $\begin{array}{c}\text { ENVIRONMENTAL SAFETY } \\
\text { AND HEALTH }\end{array}$ & & \\
\hline & Job Safety & $\begin{array}{l}\text { Safety Officer and Safety } \\
\text { Supervisor }\end{array}$ & Safety Officer \\
\hline & Substance Abuse Programs & Supervisor and foreman & Safety Officer \\
\hline & $\begin{array}{l}\text { Safety Training and } \\
\text { Orientation }\end{array}$ & $\begin{array}{c}\text { Safety Officer and Safety } \\
\text { Supervisor }\end{array}$ & Safety Officer /Project Engineer \\
\hline
\end{tabular}

Figure 2. Guide for interview participants on the extraction of information for the pilot project.

\section{Data Collection and Validation of the BPPII-Petrochemical Method}

The developed BPPII-Petrochemical method was validated through its implementation in 13 pilot projects across all project types (i.e., Construction, Maintenance, and Shutdown/Turnaround) from five petrochemical plant owners in Singapore. The pilot projects were conducted at various petrochemical plants in Singapore such as ExxonMobil, Singapore Refining Company (SRC), Chevron, Petrochemical Corporation of Singapore (PCS), Mitsui Chemicals, and Shell. The Pilot projects were selected together by the pilot workgroup members (from the plant owners) in the industry panel using a survey form as shown in Appendix A, Figures A3 and A4. The master list of projects was then shortlisted by the research team members based on the size and scope of the project. For the successful validation of the tool, the research team selected projects which are in the initial phase of construction in order 
to verify the project on-site and validate the productivity practice and their levels selected by each project team. For the data collection, a joint assessment of the BPPII-Petrochemical elements with the plant owner and contractor was carried out by the research team. The research team undertook a structured interactive interview approach for collecting data so as to obtain a clear understanding of the implementation levels from both the owner and contractor. Prior to the data collection, a pre-information sheet containing the details on the scope of the project (e.g.,: location, the scope of work, subcontractor information, data collection dates) was sent to the participants for their input. The research team also studied the scope of work with the pre-information sheet to thoroughly understand the pilot project. The project participants were also trained on the definitions of the various BPPII-Petrochemical elements before data collection.

The data was collected from 13 pilot projects (construction, maintenance, and shutdown/turnaround) from five owners and eight contractors as shown in Table 4.

Table 4. Summary of the Project Types.

\begin{tabular}{ccc}
\hline S/No & Project Type & Total \\
\hline 1. & New Construction & 5 \\
2. & Maintenance & 4 \\
3. & Shutdown Turnaround & 4 \\
& Total Number of Projects & 13 \\
\hline
\end{tabular}

\subsection{Data Analysis}

The data collected during the assessment sessions were then analyzed and meaningful inferences were ascertained. The results and recommendations were communicated to the participating organizations in a compiled BPPII-Petrochemical report. The following table (Table 5) summarizes the overall Singapore Score, category scores acquired, the maximum score, and average BPPII-Petrochemical score.

Table 5. Pilot Projects BPPII-Petrochemical Singapore Score (All Projects. No = 13).

\begin{tabular}{ccccc}
\hline S/No & Categories & Acquired Score & Maximum Score & Average Score \\
\hline I & Material Management & 178 & 323 & $54.62 \%$ \\
II & Equipment Logistics & 142 & 287 & $48.91 \%$ \\
III & Craft Information Systems & 189 & 290 & $64.94 \%$ \\
IV & Human Resource Management & 210 & 322 & $65.03 \%$ \\
V & Construction Methods & 207 & 284 & $71.53 \%$ \\
VI & Environment, Safety, and Health & 366 & 372 & $98.28 \%$ \\
& BPPII-Petrochemical score & 1292 & 1879 & $68.42 \%$ \\
\hline
\end{tabular}

The results presented in Table 5 and Figure 3 enabled a clear visualization of the BPPII-Petrochemical Scores for all the project participants. Figure 2 depicts the Actual Category BPPII-Petrochemical Score vs Maximum Category BPPII-Petrochemical Score. Based on the analysis the total BPPII-Petrochemical score was found to be in the $(68.42 \%)$ with categories such as Material Management and Equipment Logistics having low implementation levels and Environment Health and Safety being implemented effectively. Further analysis was conducted to identify the practices within the categories with low implementation level. The levels were differentiated into two types, elements averaged under level 2 were categorized as weak elements and elements averaged under level 3 were categorized as neutral elements. The categories and the elements with low implementation levels were as follows: 


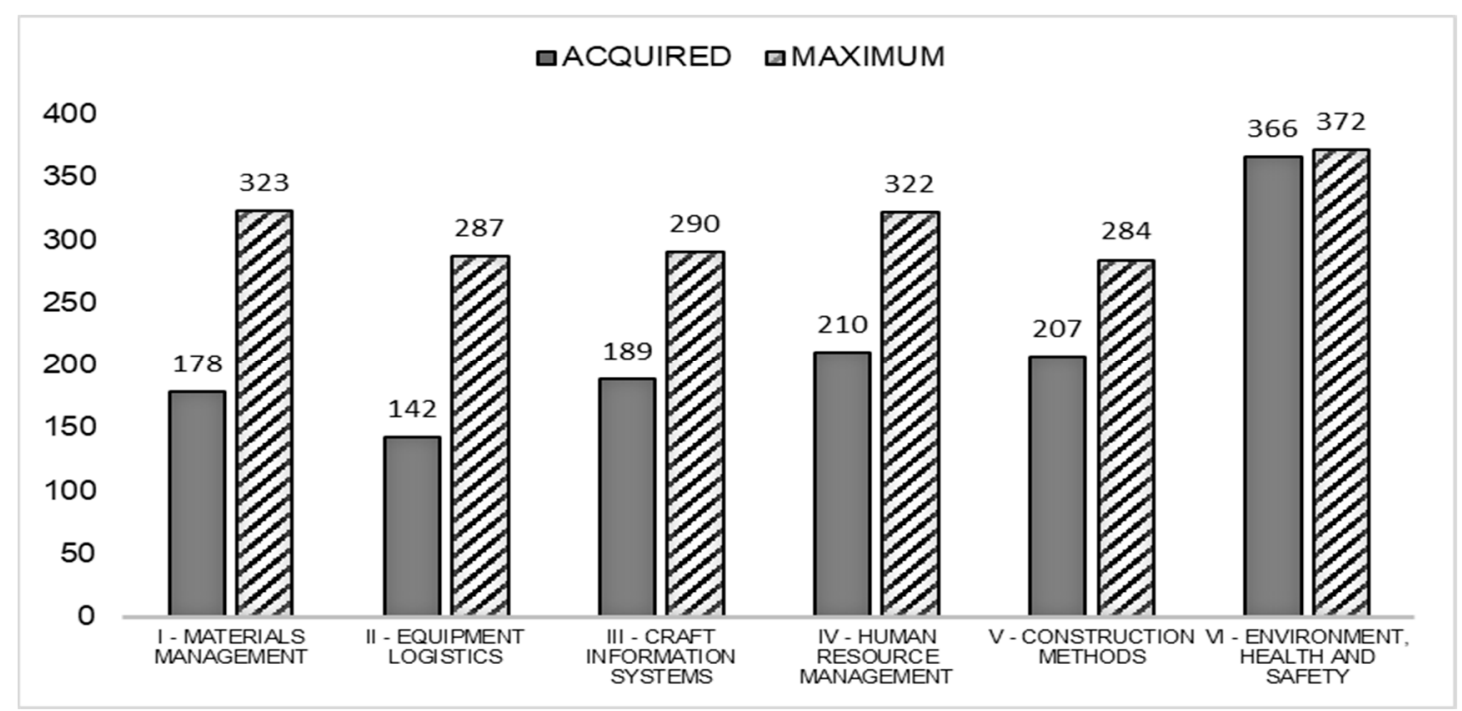

Figure 3. Actual Category BPPII-Petrochemical Score vs. Maximum Category BPPII-Petrochemical Score.

\subsubsection{Category I—Material Management}

Onsite material tracking technology, material delivery schedule, pre-fabricated material tracking and material issuing procedure and material usage tracking were noted to be the weak elements (Level 1 and 2). Elements such as project team material status database, procurement plan for materials and equipment, QA/QC inspection and assessment and NDT testing and tracking plan, and centralized warehouse on-site, including storage for fabricated materials were noted to be neutral elements (Level 3).

\subsubsection{Category II-Equipment Logistics}

Control system for tool delays, construction machinery tracking, fuel top up a schedule for equipment and machinery were noted to be the weak elements (Level 1 and 2). Elements such as tool tracking systems, on-site tool maintenance, construction machinery productivity analysis, and equipment maintenance were noted to be neutral elements (Level 3).

\subsubsection{Category III-Craft Information Systems}

Utilization of software to assist in generating work packages, project model requirements and PPMOF (Prefabrication, preassembly, modularization, and off-site fabrication) evaluation were noted to be the weak elements (Level 1 and 2). Elements such as centralized planning, work prioritization, and process control, quality control systems, and work interface review were noted to be neutral elements (Level 3).

\subsubsection{Category IV—Human Resource Management}

Career development supervisors and foremen skills development and training, teambuilding, and social activities maintain the stability of the organizational structure, while retention plan for experienced personnel and exit interviews were noted to be neutral elements (Level 3).

\subsubsection{Category V—Construction Methods}

Equipment positioning strategy was noted to be the weak element (Level 1 and 2). Elements such as work schedule strategies, schedule execution and management, dynamic site layout plan, new equipment investigation, new material technologies investigation, and new information systems investigation were noted to be neutral elements (Level 3). 


\subsection{Recommendations for Improvement}

In addition to providing the participant companies with a quantitative assessment of their existing planning and implementation levels, this study also provided recommendations in the following areas with low implementation levels to improve their BPPII score.

\subsubsection{Material Management}

On-site Material Tracking Technology which was noted to be poorly implemented could be improved by assigning materials to the laydown or storage areas and also recording and updating the information in a software system. Well-defined processes may be established for developing pick lists, flagging, warehouse organization, and other necessary functions. Material Delivery Schedule could be improved by automatic updating of the schedule upon receipt of new information on materials.

The study recommended tagging pre-fabricated material upon delivery and tracking them by updating the information on proprietary software internally to improve the Pre-Fabricated Material Tracking score. This software may or may not be integrated with or used by other contractors. The weak score observed in the material issuing procedure and material usage tracking could be mitigated by using a software application which is not integrated with the company's other information technology systems.

\subsubsection{Equipment Logistics}

To attain an improved control system for tool delays, the study suggested the use of a formal paper-based system for tracking tool delays. Additionally, it would be beneficial to utilize a regularlyupdated database of tracks tool delays among craft workers in the construction workforce.

Construction machinery might be tracked via the usage of GPS tracking software which allows personnel to locate machinery and send alerts to the computer system and/or mobile device when a tracked object leaves a fenced/designated zone. Weak scheduling was noted in fuel top-up for construction machinery and equipment. This could be improved by creating a fuel-top-up schedule that can be tracked by means of a software application.

\subsubsection{Craft Information Systems}

The study noted there could be better utilization of software for assistance in generating work packages. An improved software system that automatically includes the drawings and material delivery status could be used to improve the BPPII score. However, schedule, percentage completion, test and inspection status, and closure may be input manually after review of the work package. To attain a higher implementation level in project modelling, the study recommended the establishment of a static 4D model including basic updates that could be manually input based on scheduled changes. The study also suggested that the constructability review panel undertake an active exploration of opportunities for offsite pre-fabrication, modular construction, and pre-assembly.

\subsubsection{Construction Methods}

The study inferred that an enhanced equipment positioning strategy would increase the project BPPII score. This could be achieved through the use of 2D layout studies. Additionally, 3D modeling studies to aid in constructability review of the location and use of equipment may also be considered.

\subsection{Discussion of Results}

The BPPII-Petrochemical is a method and metric for assessing the planning and implementation levels of key practices needed to ensure high levels of labor and construction productivity. The BPPII-Petrochemical tool was developed to assist the project and the site management team to achieve higher planning preparedness and assess implementation levels of productive practices that can help improve construction productivity on-site. 
In the process of developing the tool with an additional thirteen elements, the research team took into account the relevant literature, as well as experts' knowledge and experience to investigate the management practices affecting on-site productivity and to identify and to also verify practices that can improve on-site productivity. During the development stage of the BPPII-Petrochemical, the research team adopted the practice of including automation and integration as the key focus areas for improving productivity in the Singapore context. The element categorization from level- 1 to level- 5 were divided into low- and high-level practice use groups for easy assessments. The measurement metrics and weights for three different project types (i.e., new construction, shutdown/turnaround, and maintenance) were specifically developed for the petrochemical projects.

In the process of validating the BPPII-Petrochemical, thirteen pilot projects were conducted in Singapore and based on the pilot project results the total BPPII-Petrochemical score was $68.42 \%$ with categories such as Material Management and Equipment Logistics having low implementation levels and Environment Health and Safety being implemented effectively. The low scores in categories such as Material Management and Equipment Logistics might be due to behavioral indicators in construction. If workers do not see management of materials or attention to the logistics of the equipment as key performance indicators then it is more likely for the scores in this area may be affected [46].

The research team's validation of the tool has established that the BPPII score has a significant relationship with construction productivity. This supports the hypothesis of Caldas et al. [11], that projects that score higher on the BPPII also experience better performance. With the validation results of the pilot studies, the research team established that an approximate baseline BPPII score of 65 percent divides high from low BPPII score groups. Therefore, if a project has a BPPII score of over 65 percent, the project can be considered to have the appropriate level of planning and implementation of productivity-improving practices. Though the Singapore BPPII score is $68.42 \%$ and the majority of the projects studied has scored over $65 \%$, the projects may be considered to have achieved the appropriate level of planning and implementation of practices. However, lower scores on categories such as Material Management (54.62\%) and Equipment Logistics (48.91\%) are considered to be the lagging indicators on the workforce front and there are numerous opportunities for improvement in these areas. In addition, the majority (seven) of the thirteen new elements were inducted into these two categories (Material Management and Equipment Logistics) as part of the tool customization. This scenario highlights the important contribution of the new elements identified as part of this study and the need for improvement on these elements. Also, the need for the development of new categories as the development of new materials, equipment's progress in the industry and by leveraging technology to improve construction productivity. Figure 4 below clearly depicts the unique contribution of this study and the distinct characteristics and implications in terms of variables and outcomes. 


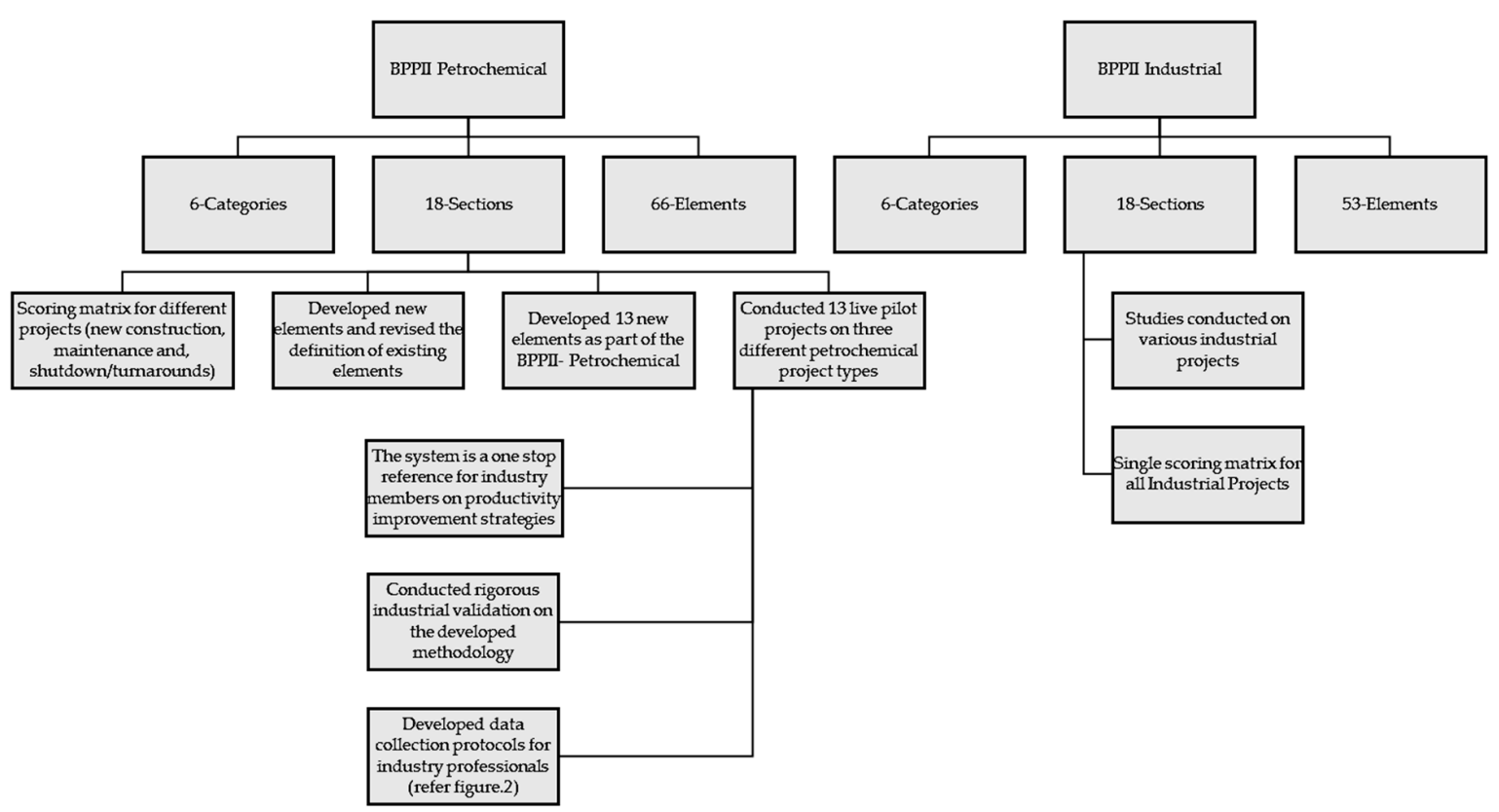

Figure 4. Comparison between the original BPPII Industrial and BPPII-Petrochemical.

The BPPII-Petrochemical is a quantitative measurement tool, which helps the industry members to understand their current position by comparing practices and its planning and implementation levels defined against an assigned relative weight. The main contribution of this study is the identification, quantification, and validation of practices that have the potential to improve productivity on petrochemical projects. The analysis of practices related to maintenance activities, shutdowns, and turnarounds is another important contribution. The previous work on best productivity practices was focused on industrial projects and covered only the construction phase [11]. The BPPII-Petrochemical has developed 13 new elements and revised the definition of existing elements together with the development of a different scoring matrix for new construction, maintenance, and shutdown/turnaround projects. The system is designed to serve as a one-stop reference for industry members on productivity improvement strategies and for the ease of assessment by the industry members, the research team has developed data collection protocol. The Singapore pilot study helped the petrochemical owners in Singapore to gauge if the contractor has the tools, systems, and practices, which facilitate high direct work hours on-site. The study also provided an indication to the research team and the project stakeholders that a contractor strong in BPPII would have tools, systems, and practices in place to have a productive workforce. By conducting the assessment of best practices based on the pilot projects and quantitative evaluation of all existing implementation levels by all stakeholders (owners and contractors). The results from this study may serve as a benchmark for future studies in the region and also a valuable contribution to the knowledge base. The main contribution of this study is the identification, quantification, and validation of practices that have the potential to improve productivity on petrochemical projects. The analysis of practices related to maintenance activities, shutdowns, and turnarounds is another important contribution. The previous work, on best productivity practices, was focused on industrial projects and covered only the construction phase. The next phase of the BPPII-Petrochemical tool would be essential to develop an additional platform to exchange best practices and ideas guiding the petrochemical industry in its transformation and helping it to address its key challenges.

\section{Conclusions and Recommendations}

The Best Productivity Practices Implementation Index for Industrial Projects (BPPII-Industrial) has been identified previously as a useful method for assessing the implementation levels of best practices that enhance productivity in industrial projects. However, for the method to be extremely useful for the 
industry, the adaption of the methodology to suit regional and project contexts (e.g.,: new construction projects, maintenance activities, shutdowns, and turnarounds) is critical. Hence, this study aimed to develop and implement the BPPII-Petrochemical methodology for use in petrochemical construction projects, maintenance activities, shutdowns, and turnarounds. In order to achieve its objective, this study (a) undertook an exhaustive literature review and surveys of industry experts to assess the applicability of the existing BPPII-Industrial to the petrochemical projects context, (b) incorporated new elements (best productivity practices) pertinent to enhanced productivity in petrochemical projects through expert interviews and examination of relevant literature, (c) developed three novel versions of the BPPII-Petrochemical method, each with unique element weights for construction projects, maintenance activities, shutdowns, and turnarounds respectively, and finally (d) conducted pilot project evaluations for validating the BPPII- Petrochemical method developed in this study at five major petrochemical plants in Singapore.

The paper summarizes the major findings and provides a percentage-based ranking among different project types. As expected, the top performer with regard to overall project types is located in the category of Environment Health and Safety $(98.28 \%)$, followed by Construction Methods $(71.53 \%)$, Human Resource Management (65.03\%), and Craft Information Systems (64.94\%) with all the scores on or above $65 \%$. However, categories such as Material Management (54.62\%) and Equipment Logistics $(48.91 \%)$ dominate the bottom of the ranking and were noted to be receiving lower attention amongst the project participants.

Among the three different project types, maintenance activities $(68.03 \%)$ were noted to be having the lowest score, compared to the Shutdowns/Turnarounds (72.35\%), and new construction projects $(65.58 \%)$. This scenario also clearly highlights the existing trend in the industry where shutdowns and turnarounds have been clearly given high priority followed by the new construction projects and the least priority lays with the maintenance activities.

This study has presented various advantages of BPPII-Petrochemical by conducting thirteen pilot projects across three different project types, in Singapore. The major contributions of this study are the development of a novel BPPII-Petrochemical method with the thirteen new elements specific to the petrochemical construction projects, maintenance activities, shutdowns, and turnarounds, and the development of a distinct scoring mechanism for all the three different project types. The combined result for all three types of projects in Singapore is $68.42 \%$. Caldas et al. [11], pointed out that the projects with above $65 \%$ can be considered more likely to have the appropriate level of planning and implementation of practices to potentially improve its labor productivity.

One of the limitations faced during the research study was the low number of projects. A higher response rate would have produced more meaningful results to conduct comparative analysis within project types. As such, an equal number of projects within different project types would have been highly desirable. Another limitation is that the sample size used in this research is relatively small, since the study was conducted in Singapore. As a result, caution should be exercised when the analysis results are interpreted and generalized. Also, the behavioral aspect of the workers was not taken into consideration for the pilot projects. Future studies that incorporate a measure for human behavior to explain the BPPII-Petrochemical scores on each of the categories. It is likely that if the workers do not see a return on investment for material management and equipment logistics, these two categories will continue to lag behind given the attention to other categories. Even though the assessment was primarily developed and tested in Singapore, most petrochemical plants investigated were from owners that operate similar facilities around the world. Therefore, the productivity practices identified in this research, as well as the proposed assessment method may apply to petrochemical facilities worldwide.

The result of the BPPII-Petrochemical research study has paved ways for owners and contractors to investigate and adopt new technology, materials, equipment, knowledge, training, and skills which are crucial for this sector of the economy. Implementation of these practices, which identifies areas for improvement, will help in creating organizational excellence and innovation in workplace 
problem-solving; thus, encouraging the site management team and the master craftsman to introduce changes in their work processes and enhance technical changes.

In conclusion, this study was performed to implement BPPII-Petrochemical as a practice implementation assessment and productivity improvement system in the petrochemical industry, with a primary focus on its potential benefits. In addition, this study investigated the use of particular management practices within the petrochemical projects in Singapore. First, the aggregate index of the BPPII-Petrochemical score on three different scores may help the industry to decide on the allocation of company resources towards productivity improvement, as compared to other areas such as occupational health and safety. Second, the individual indicators or definitions used for each element may help the stakeholders decide where specific bottlenecks exist and to identify strategies for mitigation. Finally, the existing BPPII-Petrochemical elements and their level definitions developed as part of this study should be periodically reviewed and updated in order to be in line with the improvements in the technology, materials, equipment, and workplace planning practices. The development of a customized BPPII-Petrochemical method indeed contributes towards Singapore's national initiative of marching towards an industry-specific approach and identifying specific initiatives that help to improve productivity and to be sustainable.

Author Contributions: Conceptualization, B.-G.H. and C.H.C.; methodology, C.H.C.; tool development software, P.K. and D.P.d.O.; validation, P.K., B.-G.H. and C.H.C.; formal analysis, P.K. and S.M.; investigation, P.K. and B.-G.H.; resources, B.-G.H. and C.H.C.; data curation, P.K.; writing - original draft preparation, P.K. and S.M.; writing-review and editing, C.H.C.; visualization, P.K.; supervision, B.-G.H. and C.H.C.; project administration, B.-G.H. and D.P.d.O.; funding acquisition, C.H.C. and D.P.d.O.

Funding: This research was funded by the Singapore Economic Development (EDB) and co-funded by SCIC members and ASPRI Members. NUS grant reference number R-296-000-162-597 and CII grant reference Number: UTA15-000415.

Acknowledgments: BPPII was implemented in Singapore, in collaboration with the Construction Industry Institute, the University of Texas at Austin (UT), and National University of Singapore (NUS), as part of a research project funded by the Singapore Economic Development (EDB), SCIC (Singapore Chemical Industry Council), ASPRI and co-sponsored by representatives of the Singapore process construction and maintenance sector and the energy and chemical industry.

Conflicts of Interest: The authors declare no conflict of interest.

\section{Appendix A}

In the appendix section explanations of figures of the survey forms, data collection forms, validation forms, and the snap shot of the excel tool developed and used as part of the research program is given below.

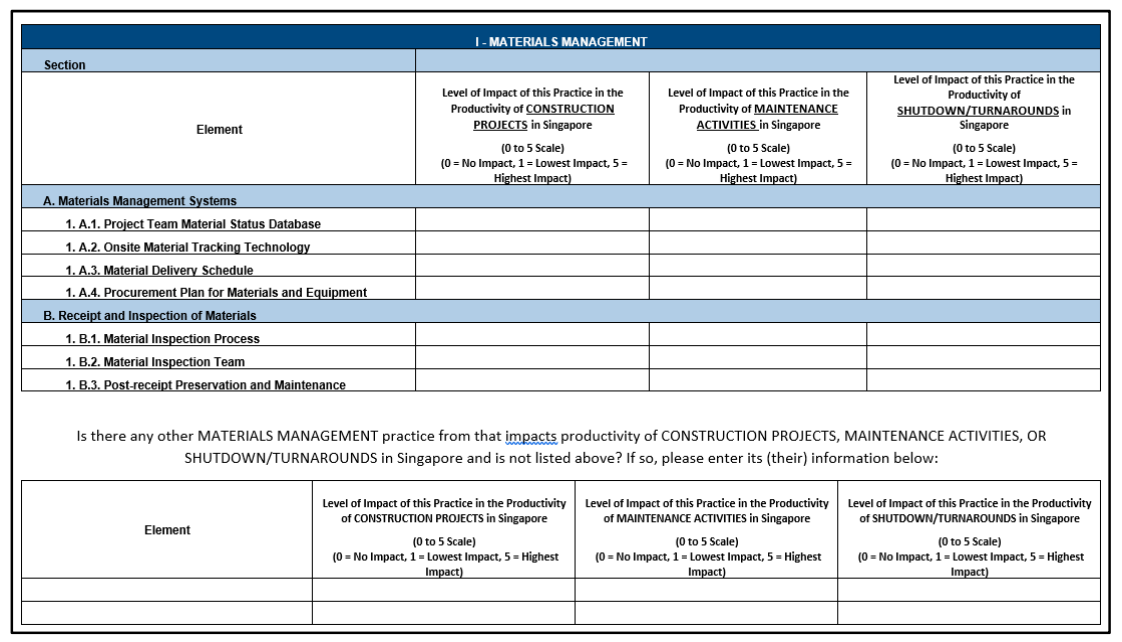

Figure A1. Survey form for existing BPPII Industrial elements. 


\begin{tabular}{|c|c|c|c|c|}
\hline \multirow{3}{*}{ s/No } & \multirow{3}{*}{ Elements } & \multicolumn{3}{|c|}{ Level of Impact of this Practice in Productivity } \\
\hline & & $\begin{array}{c}\text { NEW } \\
\text { CONSTRUCTION }\end{array}$ & MAINTENANCE & $\begin{array}{l}\text { SHUTDOWN/ } \\
\text { TURNAROUND }\end{array}$ \\
\hline & & \multicolumn{3}{|c|}{$\begin{array}{l}\text { (0 to } 5 \text { Scale) (0 = No Impact, } 1=\text { Lowest Impact, } 5= \\
\text { Highest Impact) }\end{array}$} \\
\hline & \multicolumn{4}{|l|}{ I- MATERIALS MANAGEMENT } \\
\hline & A. Material Management Systems & & & \\
\hline $1 . A .5$ & Pre-Fabricated Material Tracking & & & \\
\hline \multirow[t]{2}{*}{ 1.A.6 } & Material Issuing Procedure \& Material Usage Tracking & & & \\
\hline & B. Receipt and Inspection of Materials & & & \\
\hline 1.B.4 & $\begin{array}{l}\text { Centralized Ware House On site, Including Storage for } \\
\text { Fabricated Materials }\end{array}$ & & & \\
\hline \multirow[t]{3}{*}{ 1.8.5 } & $\begin{array}{l}\text { QA/QC Inspection \& Assessment and } \\
\text { NDT Testing \& Tracking Plan }\end{array}$ & & & \\
\hline & \multicolumn{4}{|l|}{ II - EQUIPMENT LOGISTICS } \\
\hline & B. Machinery Availability & & & \\
\hline 2.B.3 & Construction Machinery Tracking & & & \\
\hline 2.8.4 & Fuel Top up Schedule for Equipment and Machinery & & & \\
\hline \multirow[t]{4}{*}{ 2.B.5 } & On-site Construction Equipment Lay Down Area & & & \\
\hline & & & & \\
\hline & III - CRAFT INFORMATION SYSTEMS & & & \\
\hline & A. Short Interval Planning & & & \\
\hline \multirow[t]{2}{*}{ 3.A.2 } & $\begin{array}{l}\text { Centralized Planning, Work Prioritization, and Process } \\
\text { Control }\end{array}$ & & & \\
\hline & B. Workface Planning & & & \\
\hline 3.B.9 & Quality Control Systems & & & \\
\hline & & & & \\
\hline
\end{tabular}

Figure A2. Survey form for new elements in order to assign weights.

\begin{tabular}{|c|c|c|c|c|}
\hline \multicolumn{5}{|c|}{ BPPII PRE-INFORMATION SHEET } \\
\hline \multicolumn{5}{|c|}{ Name of the Project: } \\
\hline \multicolumn{5}{|c|}{ A. Project Type (Please teck one $\sqrt{ }$ ) } \\
\hline \multicolumn{5}{|c|}{ New Construction ( ) Turnaround/ Shutdown ( ) } \\
\hline \multicolumn{5}{|c|}{ Description and Characteristios of the Proposed Project: } \\
\hline \multicolumn{5}{|c|}{ 8. Contractors / Sub contractors Involved } \\
\hline S/ Mo & Contractor and Sub oontractor Name & $\begin{array}{l}\text { Work Type } \\
\text { (E.g:- } \\
\text { Mechanical, } \\
\text { Chiletc.] }\end{array}$ & $\begin{array}{l}\text { Scope of Works (E.g: Dismantling } \\
\text { Installation, etc.) }\end{array}$ & sob title of the Intervicw Particicant \\
\hline \multicolumn{5}{|l|}{1.} \\
\hline \multicolumn{5}{|l|}{2.} \\
\hline \multicolumn{5}{|l|}{3.} \\
\hline \multicolumn{5}{|l|}{4.} \\
\hline 5. & & & & \\
\hline
\end{tabular}

Figure A3. Example of the Project nomination sheet (page 1) used to sort project nomination. 


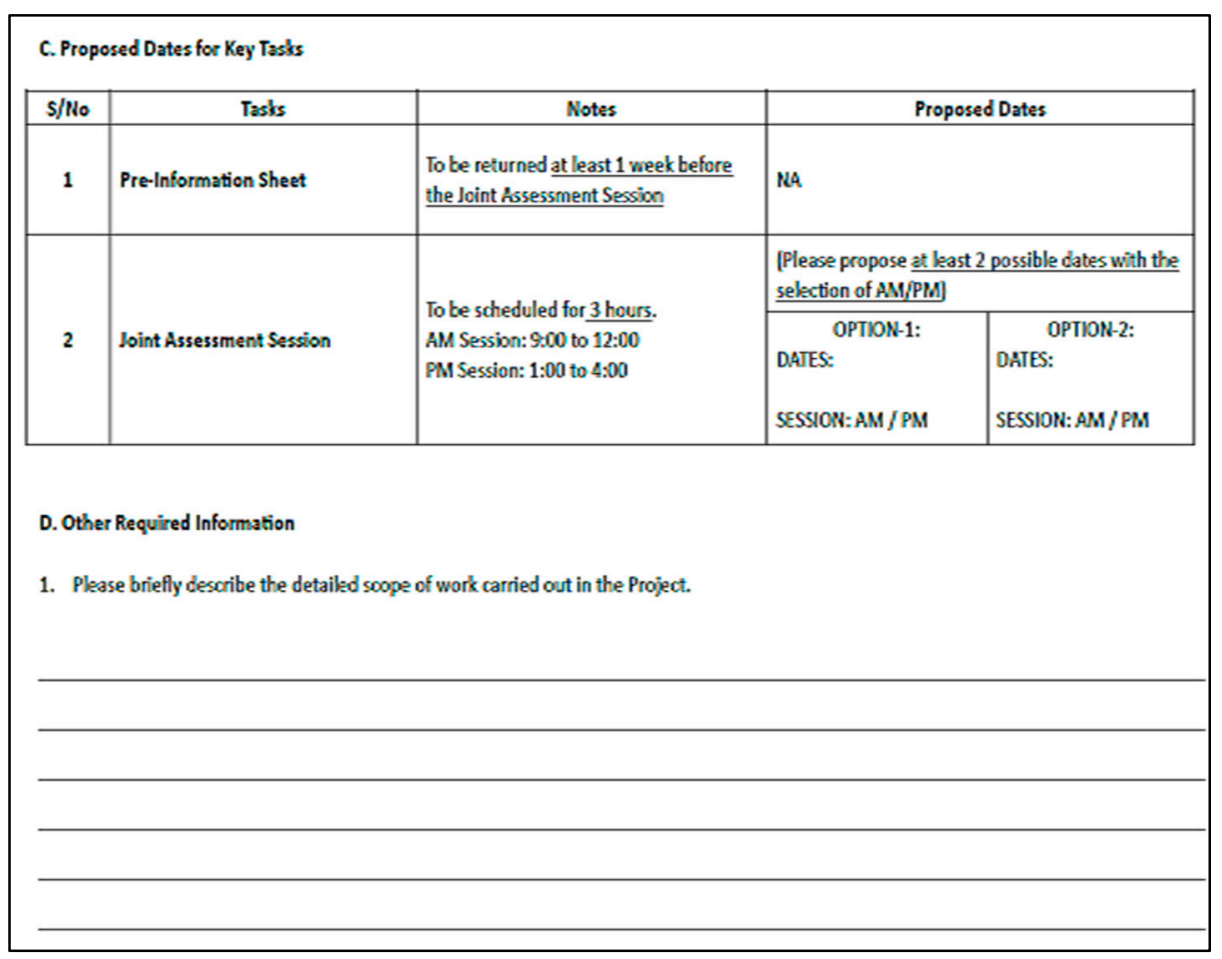

Figure A4. Example of the Project nomination (page 2) sheet used to sort project nomination.
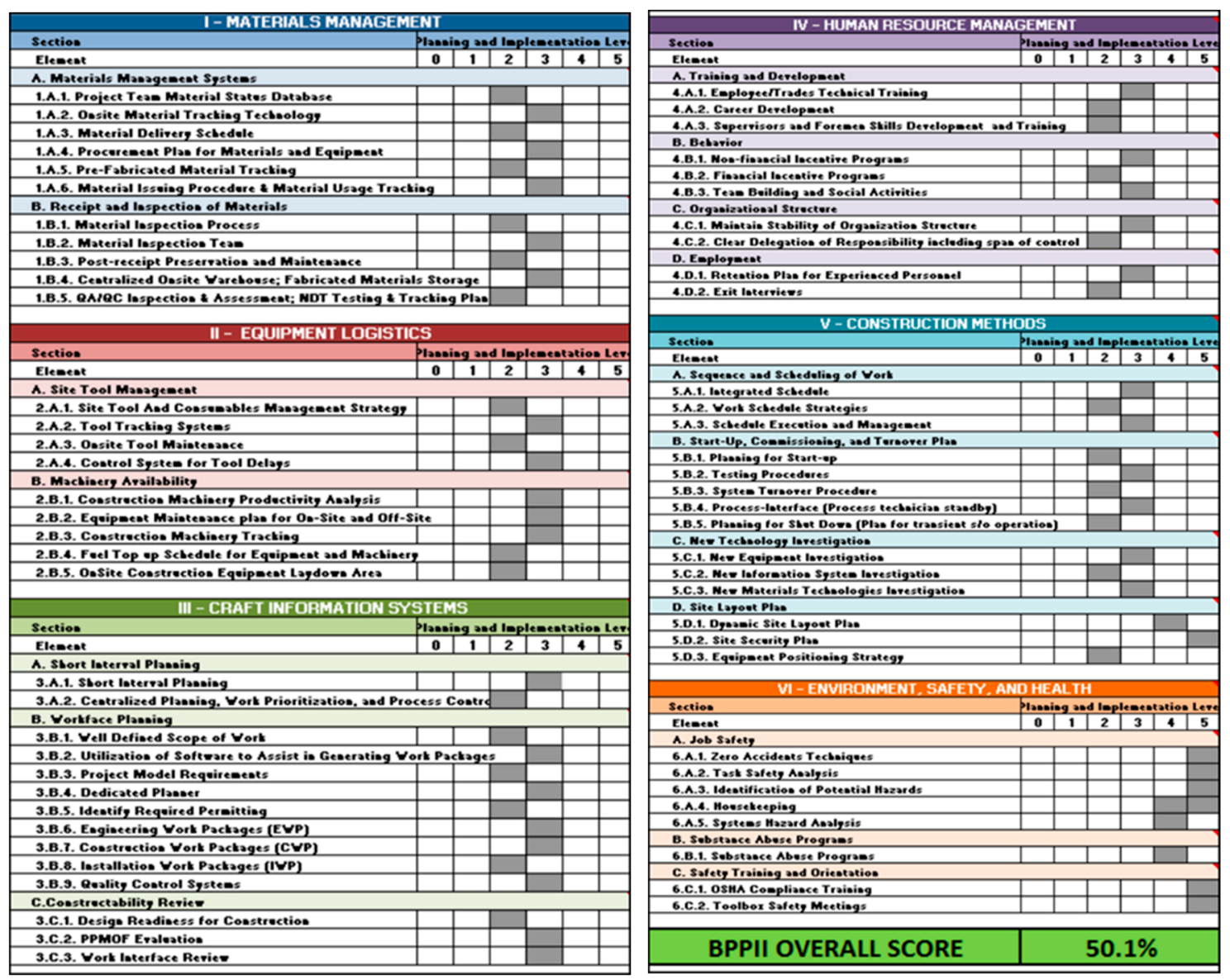

Figure A5. Example of the Self-explanatory BPPII tool used during the Pilot projects. 


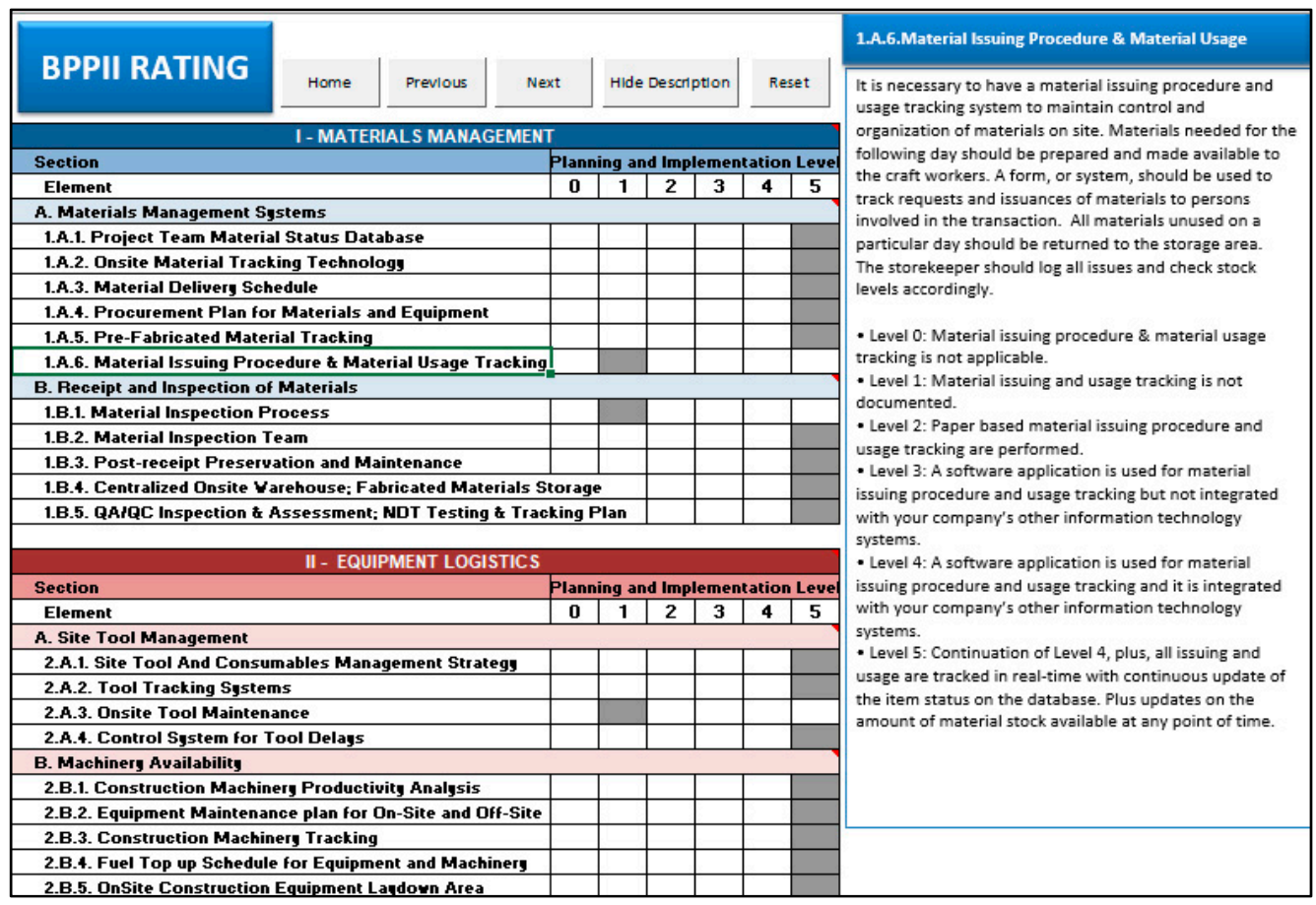

Figure A6. Example of the BPPII tool elements section.

\section{References}

1. Mctague, B.; Jergeas, G. Productivity improvement on Alberta major construction projects. Alberta Economic Development Board; Alberta Economic Development: Calgary, AB, Canada, 2003.

2. Singapore's Productivity Challenge: Singapore: Lee Kuan Yew, School of Public Policy, National University of Singapore. Available online: https:/ /lkyspp.nus.edu.sg/docs/default-source/research-centres-document/ 20160210-singapores-productivity-challenge-a-historical-perspective.pdf?sfvrsn=e00c960b_2 (accessed on 10 March 2018).

3. ESC Report of the Economic Strategies Committee 2010. Available online: https://www.mof.gov.sg/ Portals/0/MOF\%20For/Businesses /ESC\%20Recommendations /ESC\%20Full\%20Report.pdf (accessed on 18 July 2018).

4. Singapore Chemical Industry Council (SCIC). Energy \& Chemical Industry. Available online: http:/ / www. scic.sg/index.php/chemical-industry (accessed on 1 February 2018).

5. EDB Chemical Industry in Singapore, Economic Development Board (EDB). Available online: https://www. edb.gov.sg/en/our-industries/energy-and-chemicals.html (accessed on 18 February 2018).

6. Ministry of Trade and Industry (MTI). Economic Survey of Singapore 2015. Available online: https:/ / www.mti.gov.sg/ResearchRoom/SiteAssets/Pages/Economic-Survey-of-Singapore-2015/ FullReport_AES2015.pdf (accessed on 18 March 2018).

7. ASPRI. Singapore: ASPRI. Available online: http://www.aspri.com.sg/productivity-initiative/ (accessed on 19 February 2018).

8. Gouett, M.C.; Haas, C.T.; Goodrum, P.M.; Caldas, C.H. Activity Analysis for Direct-Work Rate Improvement in Construction. J. Constr. Eng. Manag. 2011, 137, 1117-1124. [CrossRef]

9. Hwang, B.; Krishnankutty, P.; Zhu, L.; Caldas, C.H.; Shounak, A.; Mulva, S. Improving Labour Productivity in Process Construction Maintenance and Shutdown/Turnaround Projects. Int. J. Constr. Eng. Manag. 2018, 1-15. [CrossRef]

10. Hewage, K.N.; Ruwanpura, J.Y. Carpentry workers issues and efficiencies related to construction productivity in commercial construction projects in Alberta. Can. J. Civ. Eng. 2006, 33, 1075-1089. [CrossRef]

11. Caldas, C.H.; Kim, J.; Haas, C.T.; Goodrum, P.M.; Zhang, D. Method to Assess the Level of Implementation of Productivity Practices on Industrial Projects. J. Constr. Eng. Manag. 2015, 141, 4014061. [CrossRef] 
12. Yu, W.D.; Cheng, S.T.; Ho, W.C.; Chang, Y.H. Measuring the Sustainability of Construction Projects throughout Their Lifecycle: A Taiwan Lesson. Sustainability 2018, 10, 1523. [CrossRef]

13. Kong, N.Y.C.; Tongzon, J. Estimating total factor productivity growth in Singapore at sectoral level using data envelopment analysis. Appl. Econ. 2006, 38, 2299-2314. [CrossRef]

14. Hwang, B.; Fang Tan, H.; Sathish, S. Capital project performance measurement and benchmarking in Singapore. Eng. Constr. Archit. Manag. 2013, 20, 143-159. [CrossRef]

15. Lim, E.; Alum, J. Construction productivity: Issues encountered by contractors in Singapore. Int. J. Proj. Manag. 1995, 13, 51-58. [CrossRef]

16. Pheng, L.S.; Gao, S.; Lin, J.L. Converging early contractor involvement (ECI) and lean construction practices for productivity enhancement: Some preliminary findings from Singapore. Int. J. Prod. Perform. Manag. 2013, 64, 831-852. [CrossRef]

17. Hwang, B.; Soh, C.K. Trade-Level Productivity Measurement: Critical Challenges and Solutions. J. Constr. Eng. Manag. 2013, 139, 4013013. [CrossRef]

18. Newlin, J.S. Effect of Enterprise Resource Implementation on Organizational Productivity. Air Force J. Logist. 2009, 33, 34 .

19. Oglesby, C.H.; Parker, H.W.; Howell, G.A. Productivity Improvement in Construction; McGraw-Hill: New York, NY, USA, 1989; ISBN 0070478031.

20. Maloney, W.F. Productivity Improvement: The Influence of Labor. J. Constr. Eng. Manag. 1983, 109, 321-334. [CrossRef]

21. Koch, M.J.; McGrath, R.G. Improving Labor Productivity: Human Resource Management Policies do Matter. Strat. Manag. J. 1996, 17, 335-354. [CrossRef]

22. Thomas, H.R.; Završki, I. Construction Baseline Productivity: Theory and Practice. J. Constr. Eng. Manag. 1999, 125, 295-303. [CrossRef]

23. Loosemore, M. Improving construction productivity: A subcontractor's perspective. Eng. Constr. Archit. Manag. 2014, 21, 245-260. [CrossRef]

24. Nasir, H.; Haas, C.T.; Caldas, C.H.; Goodrum, P.M. An Integrated Productivity-Practices Implementation Index for Planning the Execution of Infrastructure Projects. J. Infrast. Syst. 2016, 22, 4015022. [CrossRef]

25. Zhang, D.; Nasir, H.; Haas, C.T. Development of an internal benchmarking and metrics model for industrial construction enterprises for productivity improvement. Can. J. Civ. Eng. 2017, 44, 518-529. [CrossRef]

26. Caldas, C.H.; Menches, C.L.; Reyes, P.M.; Navarro, L.; Vargas, D.M. Materials Management Practices in the Construction Industry. Pract. Period. Struct. Des. Constr. 2015, 20, 4014039. [CrossRef]

27. Nasir, H.; Haas, C.T.; Rankin, J.H.; Fayek, A.R.; Forgues, D.; Ruwanpura, J. Development and implementation of a benchmarking and metrics program for construction performance and productivity improvement. Can. J. Civ. Eng. 2012, 39, 957. [CrossRef]

28. Kang, Y.; O’Brien, W.J.; Dai, J.; Mulva, S.P.; Thomas, S.P.; Chapman, R.E.; Butry, D. Interaction Effects of Information Technologies and Best Practices on Construction Project Performance. J. Constr. Eng. Manag. 2013, 139, 361-371. [CrossRef]

29. Thomas, H.R.; Sanvido, V.E.; Sanders, S.R. Impact of Material Management on Productivity-A Case Study. J. Constr. Eng. Manag. 1989, 115, 370-384. [CrossRef]

30. Grau, D.; Caldas, C.H.; Haas, C.T.; Goodrum, P.M.; Gong, J. Assessing the impact of materials tracking technologies on construction craft productivity. Autom. Constr. 2009, 18, 903-911. [CrossRef]

31. Yin, S.Y.L.; Tserng, H.P.; Wang, J.C.; Tsai, S.C. Developing a precast production management system using RFID technology. Autom. Constr. 2009, 18, 677-691. [CrossRef]

32. Caldas, C.H.; Torrent, D.G.; Haas, C.T. Using Global Positioning System to Improve Materials-Locating Processes on Industrial Projects. J. Constr. Eng. Manag. 2006, 132, 741-749. [CrossRef]

33. Goodrum, P.M.; McLaren, M.A.; Durfee, A. The application of active radio frequency identification technology for tool tracking on construction job sites. Autom. Constr. 2006, 15, 292-302. [CrossRef]

34. Dai, J.; Goodrum, P.M. Generational differences on craft workers' perceptions of the factors affecting labour productivity. Can. J. Civ. Eng. 2012, 39, 1018. [CrossRef]

35. Diekmann, J.E.; Krewedl, M.; Balonick, J.; Stewart, T.; Won, S. Application of Lean Manufacturing Principles to Construction; Construction Industry Institute: Austin, TX, USA, 2004; Available online: https://www.construction-institute.org/resources/knowledgebase/knowledge-areas/general-ciiinformation/topics/rt-191/pubs/rr191-11 (accessed on 26 February 2019). 
36. Pradhananga, N.; Teizer, J. Automatic spatio-temporal analysis of construction site equipment operations using GPS data. Autom. Constr. 2013, 29, 107-122. [CrossRef]

37. Costin, A.; Pradhananga, N.; Teizer, J. Leveraging passive RFID technology for construction resource field mobility and status monitoring in a high-rise renovation project. Autom. Constr. 2012, 24, 1-15. [CrossRef]

38. Berg, R.; Hinze, J. Theft and Vandalism on Construction Sites. J. Constr. Eng. Manag. 2005, 131, 826-833. [CrossRef]

39. Back, W.E.; Moreau, K.A. Cost and Schedule Impacts of Information Management on EPC Process. J. Manag. Eng. 2000, 16, 59-70. [CrossRef]

40. Foundation, I. Guidelines for Practical Implementation of a Construction Quality Management System; INGAA Foundation, Inc.: Washington, DC, USA, 2014; Available online: https:/ / www.ingaa.org / File.aspx?id=23570 (accessed on 18 May 2018).

41. Shokri, S.; Ahn, S.; Lee, S.; Haas, C.T.; Haas, R.C.G. Current Status of Interface Management in Construction: Drivers and Effects of Systematic Interface Management. J. Constr. Eng. Manag. 2016, 142, 4015070. [CrossRef]

42. Lenahan, T. Turnaround, Shutdown and Outage Management: Effective Planning and Step-by-Step Execution of Planned Maintenance Operations; New edn, Butterworth Heinemann: Oxford, UK, 2006; ISBN 9780080525273.

43. Prais, S.J.; Wagner, K. Productivity and Management: The Training of Foremen in Britain and Germany. Natl. Inst. Econ. Rev. 1988, 123, 34-46. [CrossRef]

44. Hameed, A.; Khan, F.; Ahmed, S. A risk-based methodology to estimate shutdown interval considering system availability. Process Saf. Progr. 2015, 34, 267-279. [CrossRef]

45. Cho, C.S.; Gibson, E. Development of a project definition rating index (PDRI) for general building projects. In Proceedings of the Construction Congress VI: Building Together for a Better Tomorrow in an Increasingly Complex World, Orlando, FL, USA, 20-22 February 2000. [CrossRef]

46. Cox, R.F.; Issa, R.R.A.; Koblegard, K. Management's Perception of Key Behavioral Indicators for Construction. J. Constr. Eng. Manag. 2005, 131, 368-376. [CrossRef]

(C) 2019 by the authors. Licensee MDPI, Basel, Switzerland. This article is an open access article distributed under the terms and conditions of the Creative Commons Attribution (CC BY) license (http:/ / creativecommons.org/licenses/by/4.0/). 